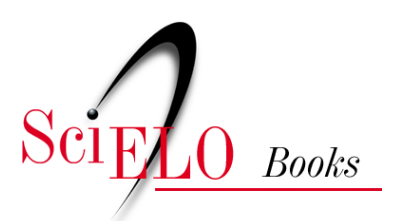

\title{
Reflexões \\ UFBA, 70: Internet no Brasil, 25
}

\author{
Nelson De Luca Pretto
}

PRETTO, N.D.L. UFBA, 70: Internet no Brasil, 25. In: Educações, culturas e hackers: escritos e reflexões [online]. Salvador: EDUFBA, 2017, pp. 203-207. ISBN: 978-85-232-2019-8.

https://doi.org/10.7476/9788523220198.0060.

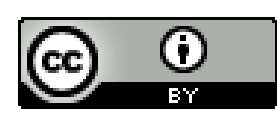

All the contents of this work, except where otherwise noted, is licensed under a Creative Commons Attribution $\underline{4.0 \text { International license. }}$

Todo o conteúdo deste trabalho, exceto quando houver ressalva, é publicado sob a licença $\underline{\text { Creative Commons }}$ Atribição 4.0.

Todo el contenido de esta obra, excepto donde se indique lo contrario, está bajo licencia de la licencia $\underline{\text { Creative }}$ Commons Reconocimento 4.0. 
tos - e não falo nem dos privados! - amarrados a editais que especificam o que se pesquisará e até as suas metodologias, comprometendo a própria pesquisa e, com isso, a autonomia da universidade. Inicia-se uma busca alucinada pela captação de recursos e as soluções mirabolantes propostas pelo governo federal são as parcerias público-privadas que comprometem a Universidade e, o pior, a comprometem por dentro. Impera a lógica do cada um cuidando de si para que as condições individuais sejam garantidas e, com isso, a ideia de excelência, onde são "premiados os melhores" em detrimento daqueles que não conseguem atingir os tais índices de produtividade, exatamente por não terem as condições concretas para a produção científica, tecnológica e cultural. Com isso, os grupos de excelência conseguem mais recursos e, num círculo vicioso, instala-se um abismo interno entre os tais grupos de ponta e os demais. Dos grupos de excelência, passamos para as universidades de excelência, que, tendo melhor desempenho, passam a ter mais verbas. Triste lógica de privilegiar os privilegiados!

A UFBA, nos seus 60 anos, para vislumbrar um futuro mais presente, precisa retomar caminhos aparentemente fora de moda porque incompatível com a onda neoliberal que domina as políticas públicas em todos os campos. Seu passado pode se constituir, quem sabe, no nosso contraponto à perspectiva de universidade-empresa, aquela que lida com as ideias como mercadoria.

\section{UFBA, 70: Internet no Brasil, 25}

A Universidade Federal da Bahia (UFBA) comemorou, em 2016, seus 70 anos de criação, com um permanente debate sobre o seu próprio futuro. 
A internet no Brasil fez 25 anos, tendo nascido nos idos de 1992, coisa que parece muito distante, mas que aconteceu há apenas alguns anos.

A UFBA tem o peso dos seus 70 e, consequentemente, desafios no seu movimento, mas caminha. A internet, com seus 25 , em plena jovialidade, corre, corre muito e se transforma quase que cotidianamente. Portanto, dois desafios: um ligado à lentidão e outro à aceleração.

A partir do decreto presidencial de 8 de abril de 1946 (Decreto-Lei no 9.155), a UFBA foi criada, agregando as unidades isoladas que em Salvador já existiam desde 1808 - a Escola de Cirurgia da Bahia, fundada por D. João VI, que a instalou no vetusto prédio no Terreiro de Jesus, no centro histórico de Salvador.

Conforme nos conta a colega professora e historiadora Antonietta D’Aguiar Nunes, em um capítulo de livro Ufba: do século XIX ao século XXI (TOUTAIN; SILVA, 2010), o referido decreto presidencial foi fruto dos esforços do poderoso médico da Escola de Medicina, filho de família tradicional da Bahia e com fortes ligações com o poder nacional. Era o doutor Edgard do Rego Santos, que, para tanto, reuniu as "faculdades de: Medicina, as chamadas escolas anexas de odontologia e farmácia, a de direito, a Politécnica, a de Ciências econômicas e a de filosofia, que houvera sido criada em 1941 por Isaías Alves”. Sem dúvida, essa foi uma ação bem articulada de Edgard Santos, fundador da UFBA, que a reitorou pelos seus primeiros 15 anos, não sem muitos confrontos internos e externos.

Ao longo dos anos, a UFBA reinou no estado da Bahia como a única e principal instituição de pesquisa e ensino superior pública. Hoje, tem que dividir espaço com 12 instituições públicas de ensino superior, o que é muito bom, tanto para o estado como um todo como para a própria UFBA, que pode, assim, deixar de se sentir superior e procurar uma ação mais articulada com as demais instituições públicas do estado. Mas o desafio não é pequeno. De um lado, temos as insuficiências crônicas do sistema, centrado em uma lógica burocrática que dificulta qualquer ação. Com a redução violenta das verbas de custeio, as universidades brasileiras vivem praticamente dos recursos captados por projetos coordenados por professores isolados ou agrupados em laboratórios. Assim, a pesquisa passa a ser gerida de fora, a partir das definições dos editais. 
Usar recursos da Fundação de Apoio à Pesquisa no Estado da Bahia (Fapesb) demanda uma verdadeira peregrinação. Comprar com base nos pregões impõe a aquisição de produtos inadequados e de baixa qualidade. Mas esses são os problemas mais estruturais, que não seriam tão dramáticos se não enfrentássemos outro muito maior: a vinculação do professor universitário aos programas de pós-graduação centrados, cada vez mais, numa lógica produtivista, que praticamente impede a produção coletiva e colaborativa. A neura por publicar, com as regras do número de coautores possíveis, com a não valorização das publicações de colegas de um mesmo programa e tantos outros entraves, tem estimulado um comportamento cada vez mais individualista e egoísta.

Dura tem sido a vida na UFBA e nas universidades brasileiras!

Mas, há não muito tempo atrás, participei de uma experiência coletiva que merece ser trazida para essas celebrações. Uma ação que, mais uma vez insisto, se constitui em uma verdadeira política de Estado: o processo de implantação da internet no país.

Foi uma honra enorme estar como assessor do reitor Luiz Felippe Perret Serpa nos anos 1990 e ter tido a oportunidade de ajudar a turma do bravo Centro de Processamento de Dados (CPD) - hoje, Superintendência de Tecnologia da Informação (STI) - da UFBA a implantar a internet na Bahia e no Brasil. Felippe Serpa, com sua pró-reitora Nice Americano da Costa Costa Pinto, braço duro na gestão da UFBA naquele período, propôs ao Conselho Universitário dar prioridade absoluta ao processo de informatização da universidade. Isso aprovado, aquele ficou sendo o nosso mantra do período e, assim, o trabalho que já vinha sendo feito desde o final dos anos 1980, por Claudete Alves, Aloísio Reis, Luiz Cláudio Mendonça, Antonio Carlos Atta e muitos outros, foi sendo intensificado e, mais do que tudo, institucionalizado. Para além da UFBA, articulávamos com o mesmo empenho a rede no estado inteiro. Era essa a correta orientação do nosso comandante em chefe Tadao Takahashi, outro mão de ferro que fez diferença na implantação daquilo que, como mencionei, considero uma correta política de Estado. Deu no que deu: o sucesso da internet no Brasil com a Rede Nacional de Pesquisa (RNP) e o Comitê 
Gestor da Internet (CGI) - este último sob ataque nesse momento difícil que vive a democracia brasileira.

Na UFBA, lembro, com uma alegria enorme, de instalar, com a ajuda dos colegas professores Sílvio Loureiro e Imbiriba, cabos pelas grossas paredes do quase centenário prédio da Reitoria, construído nos anos 1950. Isso para ali poder instalar um computador conectado à internet que possibilitasse ao Reitor Felippe Serpa convocar a imprensa para anunciar, creio que em 1995, o resultado do vestibular disponível na internet, e não mais - os antigos lembram bem - nas edições extraordinárias dos jornais impressos, que publicavam cadernos especiais com a listagem dos alunos aprovados. Essas listagens eram impressas e afixadas na entrada da Reitoria, para onde jovens e suas famílias se deslocavam, ansiosos para encontrar seus nomes nas pouco mais de três mil vagas que a UFBA oferecia naquela época. Importante destacar que devemos ter sido umas das primeiras universidades a isso fazer.

Mas fizemos muito mais. Criamos o Comitê Gestor da rede que se denominamos na época de Rede Bahia. Sim, era esse o nome da nossa rede! Mas não nos preocupamos em registrá-lo, de modo que, posteriormente, esse nome passou a ser a marca da rede de televisão que foi criada pela família do ex-governador e ex-senador Antônio Carlos Magalhães, quando este trouxe para a sua emissora a transmissão da Rede Globo de Televisão na Bahia, retirando-a da sua concorrente, a tradicional TV Aratu. Perdemos o nome, mas não perdemos a grandeza dessa construção. Queríamos que a Bahia caísse na rede - aliás, título de um artigo meu com o, à época, orientando de iniciação científica Messias Bandeira, hoje professor e diretor do Instituto de Humanidades, Artes e Ciências Professor Milton Santos (Ihac/UFBA). Como coordenador desse Comitê Gestor, articulamos a montagem de uma rede com capilaridade para cobrir o estado inteiro, o que, lamentavelmente, pouco andou desde aquele tempo até os dias de hoje.

O desenho que propúnhamos para o backbone estadual guardo até hoje com muito carinho e, um dia, ainda me debruçarei para a escrita com mais detalhe dessa história. 
Enfim, para encurtar este texto que celebra esses aniversários e se constitui em um breve rabisco de memória, registro que o diploma que recebi como um dos Construtores da Internet no Brasil, dado durante o Fórum da RNP, em outubro deste ano de 2017, é um diploma de e para todos os bravos lutadores de instituições públicas que acreditavam - e ainda acreditam - que o Estado tem muito a fazer em todas as áreas, especialmente quando nos referimos à infraestrutura e ao fortalecimento da cidadania.

Salve os 25 anos da internet. Salve os 70 anos da UFBA. Salve! E salvem as nossas universidades e institutos de pesquisas públicas, que amargam com os recentes cortes de verbas propostos pelo governo federal.

Precisamos de força e garra para celebrar e continuar lutando na defesa de um Estado forte, que considere prioridades a justiça e a igualdade social, um Estado que não privilegie os já tão privilegiados, coisa que estamos vendo acontecer, com tanta ganância, cinismo e desenvoltura, nesse governo ilegítimo que aí está.

\section{Ainda bem que não houve nada}

Sábado e domingo passado, ouvi e li inúmeras vezes a frase título deste artigo, como consolo por ter sido assaltado na sexta-feira, quando estacionava o meu carro para almoçar. Era uma e meia da tarde, numa movimentada rua entre a orla e o Chame Chame; já estava a uns 50 metros do carro e caminhava tranquilamente em direção ao restaurante, quando fui abordado por um homem bem vestido, de arma em punho que, imagino, de algum lugar ali perto, observava os meus movimentos. Rapidamente, 